\title{
Gadolinium-based layered double hydroxide and graphene oxide nano-carriers for magnetic resonance imaging and drug delivery
}

\author{
Muhammad Sani Usman ${ }^{1}$, Mohd Zobir Hussein ${ }^{1 *}$, Sharida Fakurazi ${ }^{2,3}$ and Fathinul Fikri Ahmad Saad ${ }^{4}$
}

\begin{abstract}
Gadolinium (Gd)-based contrasts remain one of the most accepted contrast agents for magnetic resonance imaging, which is among the world most recognized noninvasive techniques employed in clinical diagnosis of patients. At ionic state, $\mathrm{Gd}$ is considered toxic but less toxic in chelate form. A variety of nano-carriers, including gadolinium oxide $\left(\mathrm{Gd}_{2} \mathrm{O}_{3}\right)$ nanoparticles have been used by researchers to improve the T1 and T2 contrasts of MR images. Even more recently, a few researchers have tried to incorporate contrast agents simultaneously with therapeutic agents using single nano-carrier for theranostic applications. The benefit of this concept is to deliver the drugs, such as anticancer drugs and at the same time to observe what happens to the cancerous cells. The delivery of both agents occurs concurrently. In addition, the toxicity of the anticancer drugs as well as the contrast agents will be significantly reduced due to the presence of the nano-carriers. The use of graphene oxide $(\mathrm{GO})$ and layered double hydroxides $(\mathrm{LDH})$ as candidates for this purpose is the subject of current research, due to their low toxicity and biocompatibility, which have the capacity to be used in theranostic researches. We review here, some of the key features of LDH and GO for simultaneous drugs and diagnostic agents delivery systems for use in theranostics applications.
\end{abstract}

Keywords: Layered double hydroxides, Graphene oxide, Drug delivery, Gadolinium contrast, Magnetic resonance imaging (MRI)

\section{Background}

There are various modes of cancer therapy, such as chemotherapy, immunotherapy and radiotherapy. Notwithstanding, the challenge of successful cancer therapy is still existing. Chemotherapy is the most accepted method of cancer therapy amongst the three modes; this is due to availability of various chemotherapeutic agents. However, the major challenge of this method is the chemotherapeutic agents, which do not target the cancerous cells alone but normal cells are also vulnerable to the cytotoxic effects of chemotherapeutic agents [1].

\footnotetext{
*Correspondence: mzobir@upm.edu.my

${ }^{1}$ Materials Synthesis and Characterization Laboratory, Institute of Advanced Technology (ITMA), Universiti Putra Malaysia, 43400 Serdang, Selangor, Malaysia

Full list of author information is available at the end of the article
}

Nanotechnology is a promising field of research, especially in the area of the so-called nanomedicine [2-4]. In recent years, 2D inorganic nanolayers such as layered double hydroxides, graphene and graphene oxide, and metal nanoparticles-based nano-carriers have been used in various drug delivery applications. Their advantages are the reduction in toxicity and improvement of efficacy of chemotherapeutic drugs, which are known to be highly toxic to human cells. Lately, efforts have been made by some researchers to simultaneous dope contrast agents such as gadolinium ion into the aforesaid nanocarries for theranostic applications [5-9].

Layered double hydroxide (LDH) is a class of inorganic nanolayers [10] and one of the most commonly used nano-carriers in drug delivery systems. LDH is an inorganic 2D layered material with interlayer exchangeable anions [11], with the general formula, 


$$
\left[\mathrm{M}_{1-\mathrm{x}}^{2+} \mathrm{M}_{\mathrm{x}}^{3+}(\mathrm{OH})_{2}\right]_{\mathrm{x}}+\left[\mathrm{A}^{\mathrm{n}-}\right] \mathrm{x} / \mathrm{n} \cdot\left[\mathrm{mH}_{2} \mathrm{O}\right]
$$

where $\mathrm{M}^{2+}$ and $\mathrm{M}^{3+}$ represent the divalent and trivalent metal cations respectively, and $+\left[\mathrm{A}^{\mathrm{n}-}\right] \mathrm{x} / \mathrm{n}$ represents the interlayer exchangeable anions [11-13]. The inner layers also consist of water molecules which assist in uptake of molecules [14]. LDH synthesis is usually carried out from precursor solutions of the metal salts under alkali $\mathrm{pH}$ moderator.

Graphene oxide is a derivative of graphene, a nanomaterial with two dimensions (2D) and an arrangement of $\mathrm{sp}^{2}$-bonded carbon atoms. It has stupendous properties such as optical, electronic and thermal stability. GO is formed when the hydrogen atoms are replaced by oxygen atoms during the chemical synthesis. The Hummer's method is the universally adopted method of GO synthesis from graphite by strong oxidation of the latter $[15,16]$. Currently, a lot of effort is been put into exploration of prospective graphene-based materials in biomedical applications, such as nano-carriers for drug and gene delivery, biosensing and bioimaging applications [17].

\section{Application of LDH in drug delivery Drug delivery system}

Drug delivery system refers to the typically the use of nano-carriers as host to accommodate or load therapeutic agents as guest for delivery to specific targets. LDH is one of the most commonly used drug delivery agents. LDH has a 2D-layered structure which gives it a unique ability to intercalate and exchange anions with other materials, which enables it to be used as a drug carrier [18-20]. Another interesting property of LDH is its $\mathrm{pH}$-dependent controlled release properties. This specifically makes its resourceful in pharmaceutical applications. The synthesis of LDH can be conducted via two major chemical routes, which are co-precipitation or ion-exchange method; both methods can be utilized for drug intercalation and have been reported to have high drug loading capacities [21]. Nevertheless, some reports indicate different percentage loading for the methods under the same conditions [22], which may be due to the nature of the therapeutic agents. Co-precipitation is the most adopted technique for LDH synthesis, due to its drug loading ability and is often considered as the easiest method. In co-precipitation method, an aqueous precursor solution of two different metal salts is prepared; to which an anionic guest and alkaline solution are simultaneously added in drop wise manner. The set-up is then kept under stirring at room temperature with continuous hydrogen flush until a $\mathrm{pH}$ between 7 and 10 is attained. The mixed solution is then put through aging process for $18 \mathrm{~h}$ at $70{ }^{\circ} \mathrm{C}$ temperature.
The slurry obtained is centrifuged/filtered, washed and oven-dried at $60-80{ }^{\circ} \mathrm{C}$. A variety of anions can be intercalated between the layers, which lead to the formation of multifunctional nanocomposites [23]. The ion exchange technique is much similar to co-precipitation method. However, in ion-exchange method, the guest anion solution is added after the LDH is prepared [22]. As stated earlier, the drug loading capacity of the methods varies based on the nature of the drug or guest anions to be intercalated. Factors such as hydrothermal treatment, aging process, sonication and microwave assisted synthesis have been reported to affect the shapes and other physico-chemical properties of the nanocomposites produced, which in turn influences the drug loading [24].

\section{Application of GO in drug delivery}

The structure of GO consists of $\mathrm{sp}^{3}$-hybridized carbons which are composed of different functional groups, such as hydroxyl, carboxyl, and epoxides. The groups are connected to the surface of the GO sheets of the $\mathrm{sp}^{2}$ bonding carbon atoms. This enables the efficient loading of aromatic materials such as anticancer drugs onto the sheets [25]. In similarity with LDH drug delivery systems, GO-based drug delivery system is also a representative of a host-guest interactions in supramolecular chemistry, where the host and the guest molecules or ions are bonded non-covalently mostly via hydrogen bonds, ionic bonds, van der Waals interactions and hydrophobic bonds [26]. In addition, GO contains a stupendous $\pi$ structure that enables noncovalent $\pi-\pi$ stacking bonding with loaded therapeutics [27]. Due to its composition, $\mathrm{GO}$ is equally capable of $\mathrm{OH}$ and $\mathrm{COOH}$ hydrogen bonding, hydrophobic bonding, embedding and surface absorption [28] with functional groups of various drugs [28]. This facilitates drug to GO bonding for the formation of the nanocomposite and eventually release of the drug in the desired $\mathrm{pH}$ [29].

As mentioned earlier, the most commonly used methods of GO synthesis are Hummers' and Hummers' modified methods [30], which are top-down chemical approach of synthesizing GO from graphite flakes. Briefly, graphite flakes and sodium nitrate are firstly mixed and concentrated sulphuric acid is then added under constant stirring and allowed to stir for about an hour. Appropriate amount of $\mathrm{KMnO}_{4}$ is slowly added to the solution at low temperature. The solution is then allowed to stir further for $12 \mathrm{~h}$ at a temperature of $35-50{ }^{\circ} \mathrm{C}$. The solution is then diluted with $500 \mathrm{~mL}$ of deionized water. Treatment with $30 \% \mathrm{H}_{2} \mathrm{O}_{2}$ is followed. The final suspension is then washed with $\mathrm{HCl}$ and $\mathrm{H}_{2} \mathrm{O}$, filtered and dried at low temperature. GO synthesis is conducted with caution to prevent explosion [31]. 


\section{Gadolinium-based nanodelivery system for MR imaging and drug delivery}

Magnetic resonance imaging (MRI) is a powerful and one of the most commonly used clinical approaches in diagnosis of cancer patients [32]. It is equipped with high spatial resolution imaging quality with a compact size. It is noninvasive technique and considerably safe for diagnosis [33]. MRI operates under magnetic moments produced from protons in moveable molecules such as water, in a large magnetic field of high magnitude, which are transmitted under radio frequencies as signals to produce images in the MR [34]. The signals generated are of two classes, depending on the needed details of the analysis that is $\mathrm{T} 1$ and $\mathrm{T} 2$, representing spin-lattice relaxation and spin-spin relaxation mechanisms, respectively. Both signals have their unique colour contrast on different body fluids and tissues [35]. Due to poor sensitivity, MRI often requires the use of contrast agents for better image quality [33]. The contrast agents enhance the signal intensity by increasing the corresponding relaxation rates, $1 / T 1$ and $1 / T 2$, thereby resulting in a bright and dark signals for $\mathrm{T} 1$ and $\mathrm{T} 2$ respectively, taking lesser times [33, 36].

Gadolinium (Gd) is a rare-earth paramagnetic metal ion which is used in MRI due its ability to interchange freely within a magnetic field. This makes it a useful contrast agent for quality imaging of body organs. Gadolinium and gadolinium chelates [Gd-DTPA (gadopentetate dimeglumine, Magnevist)] are among the first contrast agent approved for use in MRI testing. Gd was introduced as far back as 1988 [37]. Till date, gadolinium-based contrast agents are the only FDA approved contrast agents for MRI to be used on patients with all types of cancer [38] (Table 1).

Gadolinium chelates are classified into cyclic, which are ligands such as 1,4,7,10-tetraazacyclododecane-1,4,7,10tetraacetiacid (DOTA) and 1,4,7 tris(carboxymethylaza) cyclododecane-10-azaacetylamide (DO3A) and acyclic ligands which are diethylenetriaminepentaacetic acid (DTPA) and 5,8-bis(carboxymethyl)-11-[2(methylamino)-2-oxoethyl]-3-oxo-2,5,8,11-tetraazatridecan-13-oic acid (DTPA-BMA). Earlier we have discussed how LDH and GO are used as drug carrier for pharmaceutics. Here we are going to focus on the simultaneous delivery of drugs and imaging agents or the so-called theranostic applications [39].

\section{Multimodal theranostic drug delivery systems}

Briefly, theranostics is a newly constructed term derived from the words therapeutic and diagnostic [39], occasionally referred to as theragnostics. It is used in describing the process of simultaneous diagnosis and treatment of diseases, when loaded on a nano-carrier is then referred to as theranostic drug delivery system (Fig. 1a, b). However, when only a diagnostic agent is loaded on a nano-carrier, it becomes a diagnostic delivery system [40].

Recently, researches have been focused on doping MRI contrast agents-based nanocomposites such as, Gd metal complexes/chelates or Gd metal itself, Gd oxide NPs, iron oxide and other metal nanoparticles, as T1 or T2 relaxation agents, which often involves the use of nanocarriers for delivering the complexes.

Multimodal theranostic delivery system refers to delivery system containing more than one diagnostic agents and a therapeutic agent loaded on a nanocarrier with contrast ability for two or more imaging equipments. Multimodal theranostic delivery agent is applied mostly when two or more diagnostic equipments are involved for imaging [41]. As shown in Fig. 1b, nanomaterials as carriers are capable of accommodating various materials based on the final application of the delivery system, from targeting agents, such as forlic acid (FA) to diagnostic theranostic agents for use in MRI, computed tomography $(\mathrm{CT})$, positron emission tomography-computed tomography (PET-CT), sensors and so on, and therapeutics. For instance, Zhang et al. [42] prepared a Gd-based nanocomposite using $\mathrm{Si}-\mathrm{Ti}$ nanoparticles as the carrier of the Gd and FA as the contrast agent and targeting ligand respectively, for in vivo MRI and near-infraredresponsive photodynamic therapy in cancers. The resulting nanocomposites showed improved $\mathrm{T} 1$ weighted MRI contrast. Similarly, Zhang et al. [17] in a bimodal imaging research used GO nano-sheets in the presence of polyethylene glycol (PEG) as a compatibility agent to obtain GO/BaGdF5/PEG nanocomposite. The composite showed promising T1 weighted MR and CT imaging properties. Table 2 depicts previous research works that have reported nanodelivery of contrast agents using various nanoparticles.

The use of nano-carriers as tools for transporting contrast agents has been a promising start in contrast enhancement research, even more promising is the simultaneous delivery of the contrast agents as well as therapeutic agents using the same nanocarrier (Fig. 1b). Fascinating enough, only a handful of researchers have tried to simultaneously load contrast agents and chemotherapeutic agents onto nano-carriers for drug delivery. To the best of our knowledge, the articles that have reported simultaneous loading of $\mathrm{Gd}$ or $\mathrm{Gd}$ complexes and chemotherapeutic drugs onto GO and LDH nanocarriers are presented in Table 3.

The synthesis method of LDH and GO plays a role in the loading percentage of the nano-carriers. However, the key factor is the $\mathrm{pH}$ of the system, which must be favorable for the guest material. For instance, some anticancer drugs are acidic, thus drug loading must done in acidic 
Table 1 FDA approved gadolinium-based contrast agents (GBCAs) for magnetic resonance imaging (MRI)

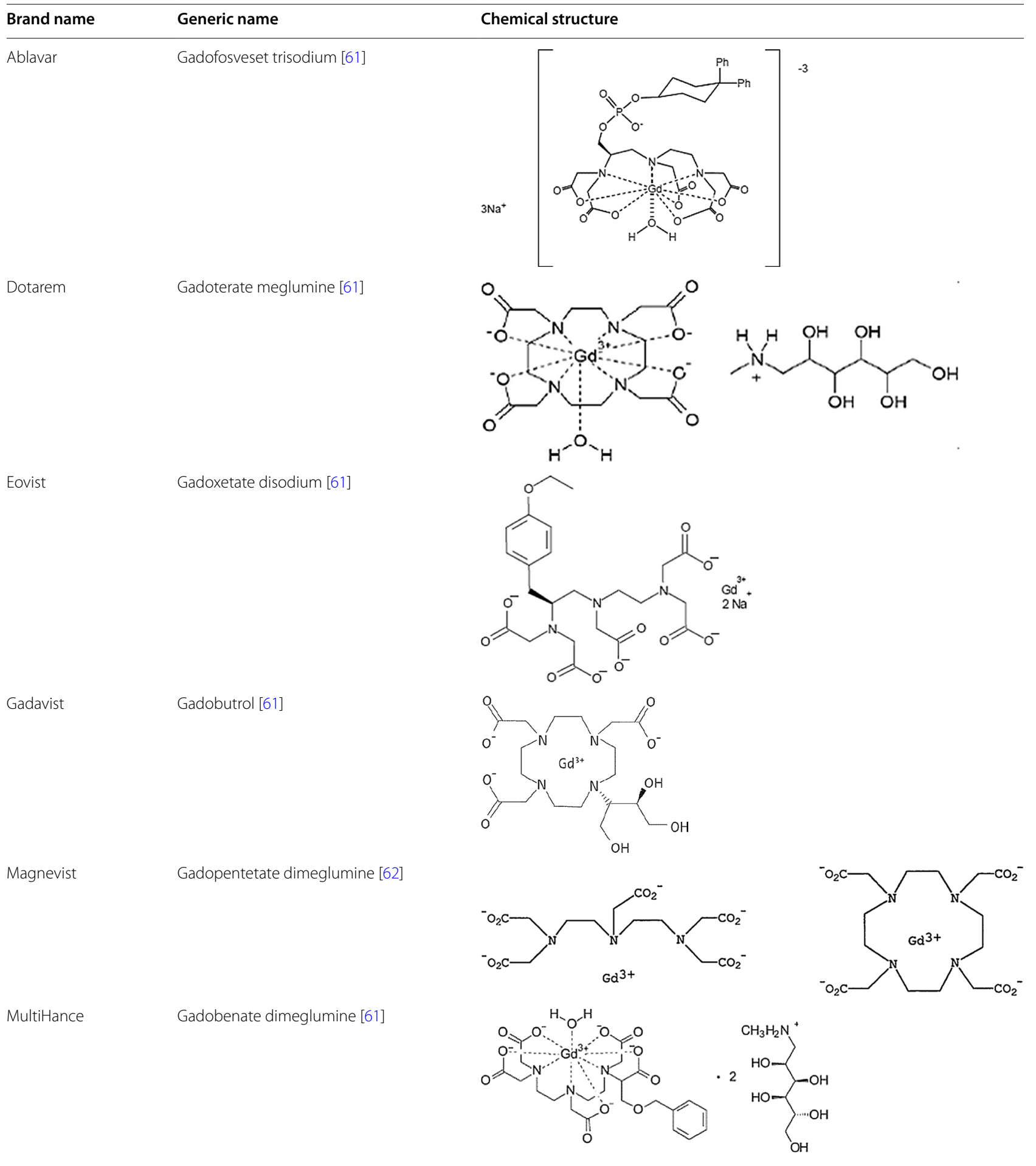


Table 1 continued

\begin{tabular}{|c|c|c|}
\hline Brand name & Generic name & Chemical structure \\
\hline Omniscan & Gadodiamide [61] & \\
\hline OptiMARK & Gadoversetamide injection [61] & \\
\hline ProHance & Gadoteridol [61] & O \\
\hline
\end{tabular}

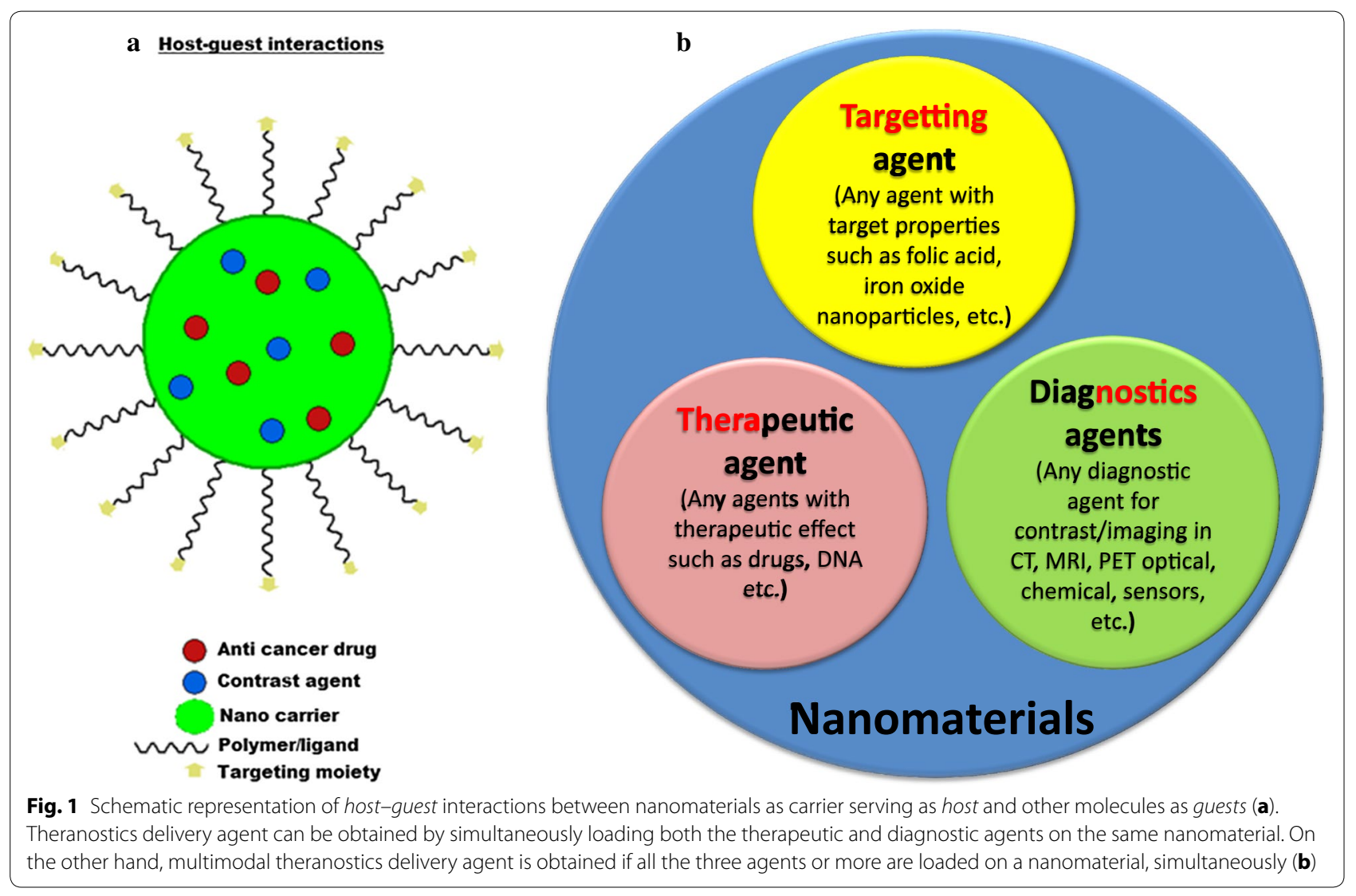


Table 2 Previous works on gadolinium-based nanoparticles/nanocomposites contrast agents

\begin{tabular}{|c|c|c|c|}
\hline Carrier & Contrast agent & Remark & Ref \\
\hline $\mathrm{GO}$ & Gd & Improved T1-weighted MRI contrast property & [17] \\
\hline $\mathrm{Si}-\mathrm{Ti} \mathrm{NPS}$ & $\mathrm{Gd}$ & Improved T1-weighted MRI contrast property & [42] \\
\hline PEG-Gd $\mathrm{O}_{3}$ & Gd & $\mathrm{Gd}_{2} \mathrm{O}_{3}$ treatment with PEG-silane showed enhanced $\mathrm{R}_{1}$ relaxivity & [63] \\
\hline Gadonanotubes & $\mathrm{Gd}$ & Nanotubes showed a R1/pH responsive MRI contrast properties & [64] \\
\hline Protein-DTPA Gd & $\mathrm{Gd}$ & Enhanced $\mathrm{T} 1$ particle relaxivities & [65] \\
\hline Gd-NPs & $\mathrm{Gd}$ & Superior contrast properties to commercial contrast agents & {$[60]$} \\
\hline $\mathrm{Gd}_{2} \mathrm{O}_{3}$ AuNPs & $\mathrm{Gd} / \mathrm{Au}$ & Nanoamplifiers showed enhanced contrast & [66] \\
\hline $\mathrm{Gd}_{2} \mathrm{O}_{3} \mathrm{NPs}$ & Gd & Intracellular MRI contrast agent & [67] \\
\hline Gd-Au NCs & $\mathrm{Gd} / \mathrm{Au}$ & Potential bimodal contrast agent & [68] \\
\hline Gd-CS DTPA & Gd & In vivo and in vitro results showed enhancement in intensity of MRI signals & [69] \\
\hline
\end{tabular}

Table 3 Gadolinium based nanocomposites for simultaneous delivery of drug and contrast agents

\begin{tabular}{|c|c|c|c|c|c|c|}
\hline Carrier & $\begin{array}{l}\text { Contrast } \\
\text { agent }\end{array}$ & Active agent & Cell type & Remark & Ref & Year \\
\hline Mg-Al-LDH & $\mathrm{Gd} / \mathrm{Au}$ & DOX & Cervical cell (Hela) & $\begin{array}{l}\text { Low cytotoxicity in vitro and good CT and } \\
\text { T1-weighted MR imaging capabilities }\end{array}$ & [43] & 2013 \\
\hline GO-PEG & $\mathrm{Gd}$ & DOX & Human liver cell (HepG2) & Shows greater tumor targeting imaging efficiency & {$[70]$} & 2012 \\
\hline NGO-PAMAM & $\mathrm{Gd}$ & EPI & Glioblastoma (U87) & $\begin{array}{l}\text { Inhibit cancer cells growth and good MRI contrast } \\
\text { for tumor identification }\end{array}$ & {$[56]$} & 2014 \\
\hline GO-DTPA & $\mathrm{Gd}$ & DOX & Human liver cell (HepG2) & $\begin{array}{l}\text { Improved MRI T1 relaxivity with better cellular MRI } \\
\text { contrast and with a substantial cytotoxicity against } \\
\text { cancer cells }\end{array}$ & {$[55]$} & 2013 \\
\hline $\mathrm{Gd}(\mathrm{OH})_{3}: \mathrm{Mn}$ & $\mathrm{Gd}$ & DOX & $\begin{array}{l}\text { Breast cancer cell (MDA- } \\
\text { MB-231) }\end{array}$ & $\begin{array}{l}\text { High cytotoxicity towards the cancer cells as well } \\
\text { promising paramagnetic activity and radiation } \\
\text { treatment for cancer }\end{array}$ & [59] & 2016 \\
\hline Fibre & Gd DTPA & Indomethacin & - & Potential theranostic agents & {$[58]$} & 2016 \\
\hline
\end{tabular}

$\mathrm{pH}$. For cellular uptake, the size and shapes of the nanocarriers play the most significant role.

This review is focused on GO- and LDH-based nanocarriers for theranostic applications because of their unique ability to either intercalate or surface-coat other materials in a host-guest supramolecular interactions. In addition, LDH can accommodate both ionic and non-ionic anticancer drugs [43] at high distribution and sustained release [24]. Figure 2 depicts how theranostic agents can be loaded onto LDH interlayers in the presence of exchangeable anions. It has been reported how nano-carriers such as LDHs have the ability to penetrate cancerous cells $[23,24]$. The positively charge outer layers of LDH and the negatively charged cell surface facilitate cell penetration through electrostatic attraction-induced endocytosis and then eventually the anti-cancer drugs are delivered [44, 45]. However, the most reported mechanism of cellular uptake of LDH is via clathrin-mediated pathways [24].

The same mechanism can be applied in contrast agents' delivery to the cancerous cells; nanocomposite cellular

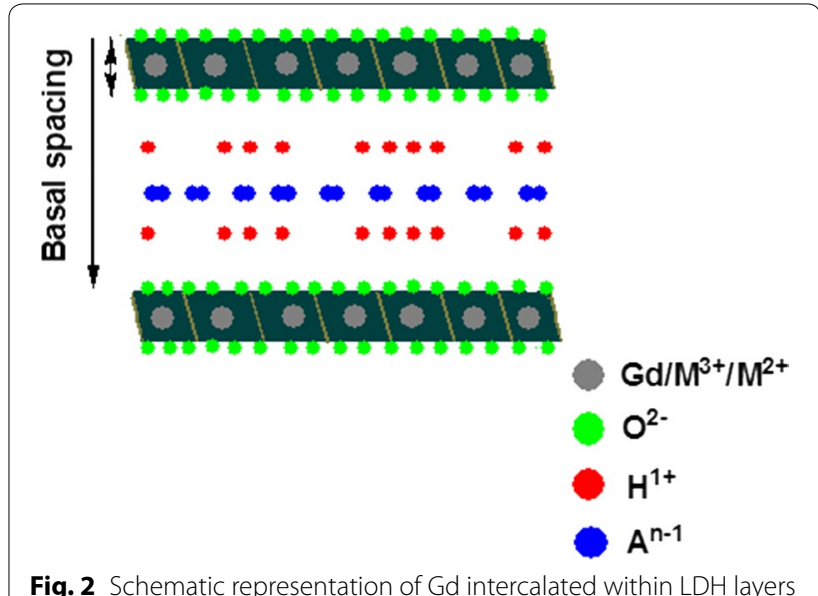

delivery can be observed [46]. In a bimodal imaging theranostic research, simultaneous loading of an anti-cancer drug doxorubicin (DOX), MRI contrast agent, Gd as well as a CT contrast agent, silver nanoparticles (AuNPs) onto 
MgAl LDH nanocomposites was carried out by Wang et al. [43]. The DOX was coated on the LDH instead of the conventional intercalation of anionic drugs via ion exchange within the $\mathrm{LDH}$ interlayers. Interestingly, AuNPs coated on the surface of the LDH-Gd nanocomposites showed much higher $\mathrm{CT}$ contrast compared to clinically approved iobitridol contrast agent. Similarly, the in vivo results of the Gd-based LDH composite depicted high T1-weighted MR imaging contrast. Loading of contrast agents into nano-carriers may not only improve the imaging but also reduce the toxicity of the agents themselves, since gadolinium for instance is relatively toxic at certain concentrations [47, 48].

GO-based nanocomposites on the other hand, have been reported to have integrated contrast agents, drugs, nanoparticles as well as other active agents $[25,49,50]$. The high surface area to volume ratio of GO provides opportunity for absorption of metallic materials, drugs and compatibilizers such as polymers, are often used to improve the interaction with other nanoparticles or materials, as stated earlier. Additionally, the thin high surface area 2D structure of GO layers also assists in encapsulating MRI contrast agents such as Gd.

Interestingly, graphene nanomaterial itself is believed to be an anti-cancer in nature [51], however, when incorporated with anticancer agents gives higher therapeutic activity. In similarity with LDH, GO also has the capacity to accommodate both therapeutic agents $[50,52,53]$ and MRI/CT contrast agents for theranostic applications at a very low toxicity level [54]. As indicated in the schematic representation in Fig. 3, the Gd is loaded onto the GO sheets via non-covalent $\pi-\pi$ stacking bonding. In the presence of polymers or ligands, hydrogen bonding often occurs depending on the nature of the functional groups of the agent/s involved. A few researchers have incorporated MRI and CT contrast agents into GO for imaging applications (Fig. 3; Table 3), by far only Zhang et al. [55] and Zhang et al. [17] have reported the synthesis of simultaneous delivery of therapeutic agents and loading of contrast agents in GO nanocomposites. In the latter, the GO was functionalized with PEG and transferrin (Tf) ligand for targeting therapy, in the presence of doxorubicin (DOX) as the anticancer agent and Gd as MRI contrast agent for a simultaneous drug delivery and diagnostic research. The GO nanocomposite loaded with Gd expressed an exceptional high quality $\mathrm{T} 1$ relative signal intensity as compared to the control used in a 1.5 Tesla (T) medical superconducting MRI system. However, in vivo MRI contrast imaging test was not conducted in their experiment. As for the former, DTPA ligand was employed to chelate the Gd contrast which facilitates bonding with the GO carrier as well as the therapeutic agent. The loaded DOX through physisorption in

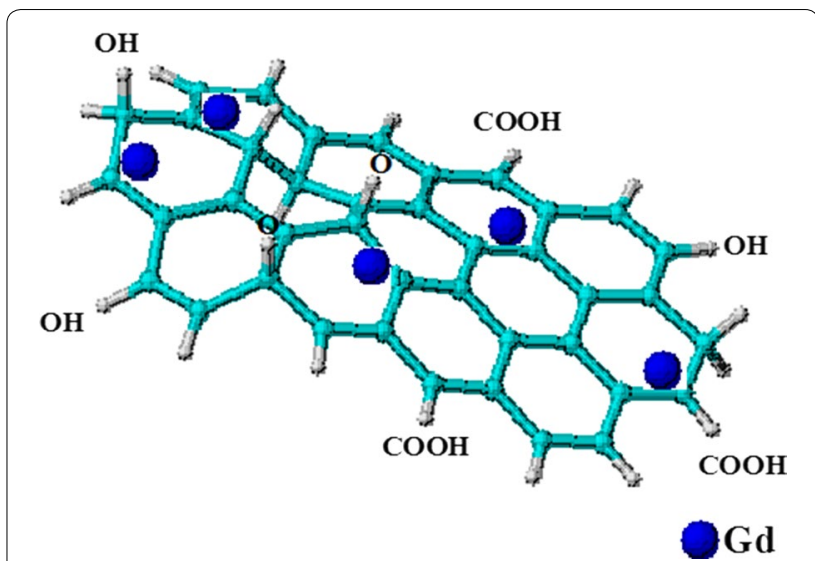

Fig. 3 Schematic representation of Gd incorporated onto GO layers

the simultaneously delivery showed relative low toxicity against human liver cell (HepG2).

In addition, MRI contrast property of the GO nanocomposites was tested using T1-weighted MRI in fluorescence imaging, which interestingly indicated improved contrast against a known commercial Gd contrast agent, Magnevist. Both articles have comparable outcomes, which are improved simultaneous theranostic imaging contrast, high loading and delivery of DOX drug. The synthesis of Gd-based nanographene oxide (NGO) was conducted by Yang et al. [56], who used functionalized $\mathrm{NGO}$ as a nanocarrier with Gd for theranostic applications. The gene targeting research was done through poly (amidoamine) dendrimer, which was used in functionalizing the $\mathrm{Gd}$.

The benefit of gene targeting is the ability for the nanocomposite to locate the cancerous cells due to the specificity of the gene targeting agents (Let-7 g miRNAs). More so, the conjugate formed between the anticancer agent Epirubicin (EPI) and the targeting agent improved the theranostic properties of the nanocomposite. Gdbased carriers loaded with anticancer drugs are indeed among the most promising potential tools in fight against cancer, having the advantages of serving as both diagnostic and chemotherapeutic agents. The most important aspect of the nanocomposite is the reduction in the toxicity of the chemotherapeutic agents, which are known to be highly cytotoxic in nature $[46,57]$. In a related theranostic research, Zhang et al. [55] conjugated DTPA onto GO nano-carrier in the presence of Gd. DTPA provides platform for the interaction between nano-carriers such as GO and Gd. DOX was used as the therapeutic agent, loaded onto the nanocomposite. The GO-DTPA-Gd/ DOX showed improved T1-weighted MRI contrast properties as well as therapeutic properties against HepG2 cells. As clearly indicated in Table 3, only a handful of 
researches are focused on fabricating the theranostic systems for simultaneous delivery of anticancer drugs and diagnostic agents.

As matter of fact, theranostic systems could be considered the most promising mechanisms for cancer research. A coaxial electrospinning method was utilized by Jin et al. [58] to synthesize core-shell fibers in the presence Eudragit as carrier for delivery of Gd-DTPA as contrast agent. The results showed promising theranostic properties.

Similarly, in a unique approach Yoo et al. [59], used $\mathrm{Mn}$ ions to produce the $\mathrm{Gd}(\mathrm{OH})_{3}$ : MnDOX nanocluster structure in the presence anticancer drug, DOX. The concept is considered promising as indicated by the in vivo toxicity results against breast cancer cells. Gd or Gd-chalets, when incorporated with nanomaterials increase their longitudinal relaxivity through increase of the rotational correlation time. This can be considered as a big advantage for MRI contrasts. Furthermore, Gd-based NPs will enjoy gradual and elongated signal due to the slow release and cellular uptake of the nanoparticles, which subsequently enhances the permeation and retention (EPR) effect. This is conformity with the results obtained by Le Duc et al. [60] in which polysiloxane-encapsulated $\mathrm{Gd}_{2} \mathrm{O}_{3}$ NPs showed perpetual MRI signal in tumor $24 \mathrm{~h}$ after injection due to the slow release properties of NPs. Fascinating enough is what these nano-carriers share in common, which is reduction in toxicity of the therapeutics as well as the diagnostics when in the nanocomposite form particularly GO and LDH, which both are capable of drug intercalation. Nonetheless, other NPs do not have such properties.

\section{Conclusion}

Gd-based contrast agents remain the most recognized MRI contrast agent clinically. They are relatively less toxic and easily removed from the body. However, certain factors such as Gd payload, tissue identification, preciseness and other artifacts associated with MRI need to be significantly reduced. Several works on nanocarriers, such as GO and LDH in developing multimodal contrast agents for MRI and CT as well as for simultaneous drug delivery to be used in theranostic applications showed promising results. These novel agents, if developed will help in diagnosis and treatment of terminal diseases, in particular cancer. They may also provide an alternative to the highly toxic chemotherapy, with the use of less toxic nano-carriers in reducing the toxicity of the anticancer agents. This paves way for a new dimension in cancer treatment and management in the near future.

\section{Abbreviations}

Gd: gadolinium; MRI: magnetic resonance imaging; CT: computed tomography; PET-CT: positron emission tomography-computed tomography; NPS: nanoparticles; GO: graphene oxide; NGO: nanographene oxide; LDH: layered double hydroxides; DOTA: 1,4,7,10-tetraazacyclododecane-1,4,7,10-tetraaceticacid; DO3A: tris(carboxymethylaza) cyclododecane-10-azaacetylamide; DTPA: diethylenetriaminepentaacetic acid; DTPA-BMA: 5,8-bis (carboxymethyl)-11-[2(methylamino)-2-oxoethyl]-3-oxo-2,5,8,11-tetraazatridecan-13-oic acid; NCs: nanocomposites; PAMAM: poly(amidoamine); PEG: poly(ethylene glycol); EPI: epirubicin; CS: chitosan; GBCAs: gadolinium-based contrast agents.

\section{Authors' contributions}

MSU: General writing of article. MZH: General editing of article. SF: Review of anticancer/cytoxicity studies of the article. FFAS: Review of MRI and contrast agents studies of the article. All authors read and approved the final manuscript.

\section{Author details}

${ }^{1}$ Materials Synthesis and Characterization Laboratory, Institute of Advanced Technology (ITMA), Universiti Putra Malaysia, 43400 Serdang, Selangor, Malaysia. ${ }^{2}$ Laboratory of Vaccines and Immunotherapeutics, Institute of Bioscience, Universiti Putra Malaysia, 43400 Serdang, Selangor, Malaysia. ${ }^{3}$ Department of Human Anatomy, Faculty of Medicine and Health Sciences, Universiti Putra Malaysia, 43400 Serdang, Selangor, Malaysia. ${ }^{4}$ Centre for Diagnostic and Nuclear Imaging, Faculty of Medicine and Health Sciences, Universiti Putra Malaysia, 43400 Serdang, Selangor, Malaysia.

\section{Acknowledgements}

The authors acknowledge support provide by Universiti Putra Malaysia.

\section{Competing interests}

The authors declare that they have no competing interests.

\section{Funding}

This research was funded by Universiti Putra Malaysia and the Ministry of Higher Education of Malaysia (MOHE) under NanoMITe Grant Vot No. 5526300.

\section{Publisher's Note}

Springer Nature remains neutral with regard to jurisdictional claims in published maps and institutional affiliations.

Received: 18 January 2017 Accepted: 23 May 2017

Published online: 30 May 2017

References

1. Reddy LH (2005) Drug delivery to tumours: recent strategies. J Pharm Pharmacol 57(10):1231-1242

2. Usman MS, Ibrahim NA, Shameli K, Zainuddin N, Yunus WMZW (2012) Copper nanoparticles mediated by chitosan: synthesis and characterization via chemical methods. Molecules 17(12):14928-14936

3. Torchilin VP (2005) Recent advances with liposomes as pharmaceutical carriers. Nat Rev Drug Discov 4(2):145-160

4. Usman MS, Zowalaty MEE, Shameli K, Zainuddin N, Salama M, Ibrahim NA (2013) Synthesis, characterization, and antimicrobial properties of copper nanoparticles. Int J Nanomed 8:4467-4479

5. Mieszawska AJ, Mulder WJ, Fayad ZA, Cormode DP (2013) Multifunctional gold nanoparticles for diagnosis and therapy of disease. Mol Pharm 10(3):831-847

6. Santra S, Kaittanis C, Santiesteban OJ, Perez JM (2011) Cell-specific, activatable, and theranostic prodrug for dual-targeted cancer imaging and therapy. J Am Chem Soc 133(41):16680-16688

7. Wang Y, Black KC, Luehmann H, Li W, Zhang Y, Cai X, Wan D, Liu S-Y, Li M, Kim P (2013) Comparison study of gold nanohexapods, nanorods, and nanocages for photothermal cancer treatment. ACS Nano 7(3):2068-2077

8. Huang X, Jain PK, El-Sayed IH, El-Sayed MA (2006) Determination of the minimum temperature required for selective photothermal destruction 
of cancer cells with the use of immunotargeted gold nanoparticles. Photochem Photobiol 82(2):412-417

9. Chen F, Hong H, Zhang Y, Valdovinos HF, Shi S, Kwon GS, Theuer CP, Barnhart TE, Cai W (2013) In vivo tumor targeting and image-guided drug delivery with antibody-conjugated, radiolabeled mesoporous silica nanoparticles. ACS Nano 7(10):9027-9039

10. Bullo S, Hussein MZ (2015) Inorganic nanolayers: structure, preparation, and biomedical applications. Int J Nanomed 10:5609

11. Sun X, Neuperger E, Dey SK (2015) Insights into the synthesis of layered double hydroxide (LDH) nanoparticles: part 1. Optimization and controlled synthesis of chloride-intercalated LDH. J Colloid Interface Sci 459:264-272

12. Ahmed AAA, Talib ZA, Hussein MZ, Flaifel MH, Al-Hada NM (2014) Influence of $\mathrm{Zn} /$ Fe molar ratio on optical and magnetic properties of $\mathrm{ZnO}$ and $\mathrm{ZnFe}_{2} \mathrm{O}_{4}$ nanocrystal as calcined products of layered double hydroxides. J Spectrosc. doi:10.1155/2014/732163

13. Barahuie F, Hussein MZ, Hussein-Al-Ali SH, Arulselvan P, Fakurazi S, Zainal Z (2013) Preparation and controlled-release studies of a protocatechuic acid-magnesium/aluminumlayered double hydroxide nanocomposite. Int J Nanomed 8(1):1975-1987

14. Chakraborty J, Roychowdhury S, Sengupta S, Ghosh S (2013) Mg-Al layered double hydroxide-methotrexate nanohybrid drug delivery system: evaluation of efficacy. Mater Sci Eng 33(4):2168-2174

15. Shen H, Zhang L, Liu M, Zhang Z (2012) Biomedical applications of graphene. Theranostics 2(3):283-294

16. Chung C, Kim YK, Shin D, Ryoo SR, Hong BH, Min DH (2013) Biomedical applications of graphene and graphene oxide. Acc Chem Res 46(10):2211-2224

17. Zhang $\mathrm{H}$, Wu H, Wang J, Yang $Y$, Wu D, Zhang $Y$, Zhang $Y$, Zhou Z, Yang $S$ (2015) Graphene oxide-BaGdF5 nanocomposites for multi-modal imaging and photothermal therapy. Biomaterials 42:66-77

18. Oh JM, Choi SJ, Lee GE, Han SH, Choy JH (2009) Inorganic drug-delivery nanovehicle conjugated with cancer-cell-specific ligand. Adv Funct Mater 19(10):1617-1624

19. Choi SJ, Oh JM, Choy JH (2010) Biocompatible nanoparticles intercalated with anticancer drug for target delivery: pharmacokinetic and biodistribution study. J Nanosci Nanotechnol 10(4):2913-2916

20. Dong L, Yan L, Hou WG, Liu SJ (2010) Synthesis and release behavior of composites of camptothecin and layered double hydroxide. J Solid State Chem 183(8):1811-1816

21. Oh JM, Park M, Kim ST, Jung JY, Kang YG, Choy JH (2006) Efficient delivery of anticancer drug MTX through MTX-LDH nanohybrid system. J Phys Chem Solids 67(5):1024-1027

22. Barahuie $\mathrm{F}$ et al (2014) Drug delivery system for an anticancer agent chlorogenate-Zn/Al-layered double hydroxide nanohybrid synthesised using direct co-precipitation and ion exchange methods. J Solid State Chem 217:31-41

23. Barahuie F, Hussein MZ, Arulselvan P, Fakurazi S, Zainal Z (2014) Development of drug delivery systems based on layered hydroxides for nanomedicine. Int J Mol Sci 15(5):7750-7786

24. Kura AU, Hussein MZ, Fakurazi S, Arulselvan P (2014) Layered double hydroxide nanocomposite for drug delivery systems; bio-distribution, toxicity and drug activity enhancement. Chem Cent J 8(1):1

25. Sun X, Liu Z, Welsher K, Robinson JT, Goodwin A, Zaric S, Dai H (2008) Nano-graphene oxide for cellular imaging and drug delivery. Nano res 1(3):203-212

26. Lodish H (2008) Molecular cell biology, 6th edn. Macmillan, London. ISBN 978-0-7167-7601-7

27. Manus LM, Mastarone DJ, Waters EA, Zhang XQ, Schultz-Sikma EA, MacRenaris KW, Ho D, Meade TJ (2009) Gd (III)-nanodiamond conjugates for MRI contrast enhancement. Nano Lett 10(2):484-489

28. Yang X, Zhang X, Liu Z, Ma Y, Huang Y, Chen Y (2008) High-efficiency loading and controlled release of doxorubicin hydrochloride on graphene oxide. J Phys Chem C 112(45):17554-17558

29. Rana VK, Choi MC, Kong JY, Kim GY, Kim MJ, Kim SH, Mishra S, Singh RP, Ha CS (2011) Synthesis and drug-delivery behavior of chitosanfunctionalized graphene oxide hybrid nanosheets. Macromol Mater Eng 296(2):131-140

30. Hakimi M, Alimard P (2012) Graphene: synthesis and applications in biotechnology-a review. World Appl Program 2(6):377-388
31. Marcano DC, Kosynkin DV, Berlin JM, Sinitskii A, Sun Z, Slesarev A, Alemany LB, Lu W, Tour JM (2010) Improved synthesis of graphene oxide. ACS Nano 4(8):4806-4814

32. Kim KS, Park W, Hu J, Bae YH, Na K (2014) A cancer-recognizable MRI contrast agents using $\mathrm{pH}$-responsive polymeric micelle. Biomaterials 35(1):337-343

33. Tang J, Sheng Y, Hu H, Shen Y (2013) Macromolecular MRI contrast agents: structures, properties and applications. Prog Polym Sci 38(3):462-502

34. Lam T, Pouliot P, Avti PK, Lesage F, Kakkar AK (2013) Superparamagnetic iron oxide based nanoprobes for imaging and theranostics. Adv Colloid Interface Sci 199:95-113

35. Campbell JL, Arora J, Cowell SF, Garg A, Eu P, Bhargava SK, Bansal V (2011) Quasi-cubic magnetite/silica core-shell nanoparticles as enhanced MRI contrast agents for cancer imaging. PLoS ONE 6(7):e21857

36. Estelrich J, Sánchez-Martín MJ, Busquets MA (2015) Nanoparticles in magnetic resonance imaging: from simple to dual contrast agents. Int J Nanomed 10:1727

37. Aime S, Caravan P (2009) Biodistribution of gadolinium-based contrast agents, including gadolinium deposition. J Magn Reson Imaging 30(6):1259-1267

38. Food U, Administration D. Information on gadolinium-based contrast agents. 2006. http://www.fda.gov/cder/drug/advisory/gadolinium agents.htm. Accessed 20 Oct 2016

39. Ahmed N, Fessi H, Elaissari A (2012) Theranostic applications of nanoparticles in cancer. Drug Discov Today 17(17):928-934

40. Xie J, Lee S, Chen X (2010) Nanoparticle-based theranostic agents. Adv Drug Deliv Rev 62(11):1064-1079

41. Liu TW, Chen J, Burgess L, Cao W, Shi J, Wilson BC, Zheng G (2011) Multimodal bacteriochlorophyll theranostic agent. Theranostics 1:354-362

42. Zhang LE, Zeng L, Pan Y, Luo S, Ren W, Gong A, Ma X, Liang H, Lu G, Wu A (2015) Inorganic photosensitizer coupled Gd-based upconversion luminescent nanocomposites for in vivo magnetic resonance imaging and nearinfrared-responsive photodynamic therapy in cancers. Biomaterials 44:82-90

43. Wang L, Xing H, Zhang S, Ren Q, Pan L, Zhang K, Bu W, Zheng X, Zhou L, Peng W (2013) A Gd-doped Mg-Al-LDH/Au nanocomposite for CT/ MR bimodal imagings and simultaneous drug delivery. Biomaterials 34(13):3390-3401

44. Kam NWS, Liu Z, Dai H (2006) Carbon nanotubes as intracellular transporters for proteins and DNA: an investigation of the uptake mechanism and pathway. Angew Chem 118(4):591-595

45. Berry CC (2005) Possible exploitation of magnetic nanoparticle-cell interaction for biomedical applications. J Mater Chem 15(5):543-547

46. Bi X, Zhang H, Dou L (2014) Layered double hydroxide-based nanocarriers for drug delivery. Pharmaceutics 6(2):298-332

47. Caravan P (2006) Strategies for increasing the sensitivity of gadolinium based MRI contrast agents. Chem Soc Rev 35(6):512-523

48. Webb JA, Thomsen HS, Morcos SK (2005) Radiology MoCMSCoESoU: the use of iodinated and gadolinium contrast media during pregnancy and lactation. Eur Radiol 15(6):1234-1240

49. Yang K, Zhang S, Zhang G, Sun X, Lee ST, Liu Z (2010) Graphene in mice: ultrahigh in vivo tumor uptake and efficient photothermal therapy. Nano Lett 10(9):3318-3323

50. Zhang L, Xia J, Zhao Q, Liu L, Zhang Z (2010) Functional graphene oxide as a nanocarrier for controlled loading and targeted delivery of mixed anticancer drugs. Small 6(4):537-544

51. Fiorillo M, Verre AF, Iliut M, Peiris-Pagés M, Ozsvari B, Gandara R, Cappello AR, Sotgia F, Vijayaraghavan A, Lisanti MP (2015) Graphene oxide selectively targets cancer stem cells, across multiple tumor types: implications for non-toxic cancer treatment, via "differentiation-based nano-therapy". Oncotarget 6(6):3553-3562

52. Wang F, Liu B, Ip ACF, Liu J (2013) Orthogonal adsorption onto nanographene oxide using different intermolecular forces for multiplexed delivery. Adv Mater 25(30):4087-4092

53. Liu J, Fu S, Yuan B, Li Y, Deng Z (2010) Toward a universal "adhesive nanosheet" for the assembly of multiple nanoparticles based on a protein-induced reduction/decoration of graphene oxide. J Am Chem Soc 132(21):7279-7281

54. Liu Z, Robinson JT, Sun X, Dai H (2008) PEGylated nanographene oxide for delivery of water-insoluble cancer drugs. J Am Chem Soc 130(33):10876-10877 
55. Zhang M, Cao Y, Chong Y, Ma Y, Zhang H, Deng Z, Hu C, Zhang Z (2013) Graphene oxide based theranostic platform for $T$ 1-weighted magnetic resonance imaging and drug delivery. ACS Appl Mater Interfaces 5(24):13325-13332

56. Yang HW, Huang CY, Lin CW, Liu HL, Huang CW, Liao SS, Chen PY, Lu YJ, Wei KC, Ma CCM (2014) Gadolinium-functionalized nanographene oxide as a nanocarrier for combined drug and microRNA delivery and magnetic resonance imaging. Nano Res. doi:10.1007/s12274-014-0412-4

57. Sun G, Zhou L, Liu Y, Zhao Z (2013) Biocompatible Gd III-functionalized fluorescent gold nanoclusters for optical and magnetic resonance imaging. New J Chem 37(4):1028-1035

58. Jin M, Yu DG, Geraldes CF, Williams GR, Bligh SA (2016) Theranostic fibers for simultaneous imaging and drug delivery. Mol Pharm 13(7):2457-2465

59. Yoo SS, Guo L, Sun X, Shaw AR, Yuan Z, Löbenberg R, Roa WH (2016) Fabrication and in vitro characterization of gadolinium-based nanoclusters for simultaneous drug delivery and radiation enhancement. Nanotechnology 27(38):385104

60. Le Duc G, Roux S, Paruta-Tuarez A, Dufort S, Brauer E, Marais A, Truillet C, Sancey L, Perriat P, Lux F (2014) Advantages of gadolinium based ultrasmall nanoparticles vs molecular gadolinium chelates for radiotherapy guided by MRI for glioma treatment. Cancer Nanotechnol 5(1):1

61. RxList, Drug index. 2016. http://www.rxlist.com. Accessed 15 Dec 2016

62. Lauffer RB, Dunham SO (2005) Contrast-enhanced diagnostic imaging method for monitoring interventional therapies. US Patent and Trademark Office. Patent No. 6,861,045

63. Fortin MA, Petoral RM Jr, Söderlind F, Klasson A, Engström M, Veres T, Käll PO, Uvdal K (2007) Polyethylene glycol-covered ultra-small Gd2O3 nanoparticles for positive contrast at $1.5 \mathrm{~T}$ magnetic resonance clinical scanning. Nanotechnology 18(39):395501

64. Hartman KB, Laus S, Bolskar RD, Muthupillai R, Helm L, Toth E, Merbach AE, Wilson LJ (2008) Gadonanotubes as ultrasensitive $\mathrm{pH}$-smart probes for magnetic resonance imaging. Nano Lett 8(2):415-419

65. Liepold LO, Abedin MJ, Buckhouse ED, Frank JA, Young MJ, Douglas T (2009) Supramolecular protein cage composite MR contrast agents with extremely efficient relaxivity properties. Nano Lett 9(12):4520-4526

66. Tian X, Shao Y, He H, Liu H, Shen Y, Huang W, Li L (2013) Nanoamplifiers synthesized from gadolinium and gold nanocomposites for magnetic resonance imaging. Nanoscale 5(8):3322-3329

67. Hedlund A, Ahrén M, Gustafsson H, Abrikossova N, Warntjes M, Jönsson Jl, Uvdal K, Engström M (2011) $\mathrm{Gd}_{2} \mathrm{O}_{3}$ nanoparticles in hematopoietic cells for MRI contrast enhancement. Int J Nanomed 6:3233-3240

68. Le W, Cui S, Chen X, Zhu H, Chen B, Cui Z (2016) Facile synthesis of gd-functionalized gold nanoclusters as potential mri/ct contrast agents. Nanomaterials 6(4):65

69. Zhang L, Liu T, Xiao Y, Yu D, Zhang N (2015) Hyaluronic acid-chitosan nanoparticles to deliver Gd-DTPA for MR cancer imaging. Nanomaterials 5(3):1379-1396

70. Shen AJ, Li DL, Cai XJ, Dong CY, Dong HQ, Wen HY, Dai GH, Wang PJ, Li YY (2012) Multifunctional nanocomposite based on graphene oxide for in vitro hepatocarcinoma diagnosis and treatment. J Biomed Mater Res A 100(9):2499-2506

\section{Submit your manuscript to a SpringerOpen ${ }^{\odot}$ journal and benefit from:}

- Convenient online submission

- Rigorous peer review

- Immediate publication on acceptance

- Open access: articles freely available online

- High visibility within the field

- Retaining the copyright to your article

Submit your next manuscript at springeropen.com 